Physica B 165\&166 (1990) 1433-1434

North-Holland

\title{
ANGULAR DEPENĐENCE OF CRITICAL FIELDS IN AS GROWN Y-Ba-Cu-O FILMS
}

\author{
H.C.YANG, H.H.SUNG and H.E.HORNG*
}

Department of Physics, National Taiwan University, Taipei, Taiwan, R.0.C *Department of Physics, National Taiwan Normal University, Taipei,Taiwan, R.O.C.

The angular dependence of the critical field and the transition temperature of the as grown films were measured at $T$ near $T_{C}$. The superconducting critical fields, $\mathrm{H}_{\mathrm{C} 2}(\mathrm{~T}, \theta)$ show a linear temperature dependence. The angular dependence of the critical field and the transition temperature are disçussed in the framework of the GL anisotropic 3D model and Tinkham $s$ 2D model of superconducting thin films.

The new CuO-based $\mathrm{YBa}_{2} \mathrm{Cu}_{3} \mathrm{O}_{\mathrm{y}}$ superconductors are characterized by a very anisotropic, layered structure and short coherence lengths. The dimensional crossover from 3D to 2D behavior is an interesting subject. This crossover should be observable in both the temperature dependence of the parallel (to the $\mathrm{Cu}-\mathrm{O}$ planes) upper critical fields and the angular dependence of the critical fields. In this work, we report the angular dependence of the transition temperature and critical fields, $\mathrm{H}_{\mathrm{c} 2}$, of $\mathrm{YBa}_{2} \mathrm{Cu}_{3} \mathrm{O}_{7-\mathrm{y}}(1-2-3$ phase $)$ thin films.

The films were in situ grown in a high pressure magnetron sputtering system using a single $\mathrm{YBa}_{2} \mathrm{Cu}_{4} \cdot{ }_{6} \mathrm{O}_{\mathrm{y}}$ target. The sputtering gas is a flowing mixture of $\mathrm{O}_{2}$ and $\mathrm{Ar}(3: 7)$ in a pressure of 150-200 mTorr. The sputtering power is 120 watts. The rate is about 0.8 A/sec. The substrates(Mgo(100)) are heated to about $700^{\circ} \mathrm{C}$ using a quartz lamp. After deposition $\mathrm{O}_{2}(1 \mathrm{~atm})$ is introduced to the system and the substrate temperature is kept at $600^{\circ} \mathrm{C}$ for one hour to increase the oxygen content. Finally the samples are cooled down to room temperature and removed from the chamber. The appearance of the sample is black and shiny. Their thicknesses are about $5600 \AA$. The $\mathrm{X}$-ray diffraction pattern of the as grown films shows preferred orientation with c-axis perpendicular to the plane of the film and all diffraction peaks can be identified with $1-2-3$ phase. The room temperature resistivity of the sample is $0.7 \mathrm{~m} \Omega . \mathrm{cm}$ and the critical current density is about $1 \times 10^{4} \mathrm{~A} / \mathrm{cm}^{2}$ at $77 \mathrm{~K}$. The transition temperature $(50 \%)=81 \mathrm{~K}$ and $\mathrm{a}$ zero resistance $=.78 \mathrm{~K}$.
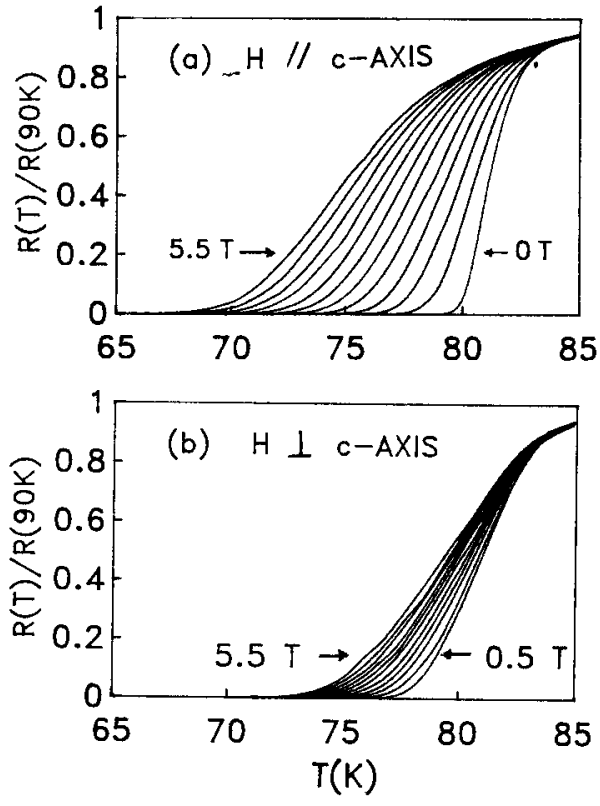

FIGURE 1

$R(T) / R(90 K)$ as a function of magnetic field (a) H $/$ c-axis (b) H $\perp$ c-axis.

Figure 1 shows the temperature dependence of resistivity for sample a in parallel and perpendicular magnetic fields. The increment in each curve is $0.5 \mathrm{~T}$. The critical field obtained from the 50\% resistive transition are observed to be linear for different orientation $\theta$ of the $c$ axis with respect to the magnetic field. The $\mathrm{H}_{\mathrm{C}}$ anisotropy data has been reported by many groups (1) for 1-2-3 single crystal and there is a general agreement for 
$\mathrm{dH}_{\mathrm{C} 2,1 \mathrm{c}} / \mathrm{dT}(-3.0 \mathrm{~T} / \mathrm{K}$ to $-4.0 \mathrm{~T} / \mathrm{K})$ and $\mathrm{dH}_{\mathrm{C} 2} / / \mathrm{C} / \mathrm{dT}(-0.4 \mathrm{~T} / \mathrm{K}$ to $-1.1 \mathrm{~T} / \mathrm{K})$. Our presént work shows $\mathrm{dH}_{\mathrm{c} 2}, \mathrm{~L}_{\mathrm{c}} / \mathrm{dT}=-3.08$ $\mathrm{T} / \mathrm{K}$ and $\mathrm{dH}_{\mathrm{C} 2}, \mathrm{c} / \mathrm{dT}=-0 . \frac{1}{9} \mathrm{~T} / \mathrm{K}$. Using the relations (2) $\xi_{\mathrm{ab}}^{2}=\Phi_{\mathrm{o}} / 2 \pi \mathrm{H}_{\mathrm{C} 2} / / /_{\mathrm{C}}$ and $\xi_{\mathrm{c}} / \xi_{\mathrm{ab}}=\mathrm{H}_{\mathrm{c} 2}, / \mathrm{c} / \mathrm{H}_{\mathrm{c} 2} \perp_{\mathrm{c}}$, where $\xi_{\mathrm{ab}}$ is paraliel to' the a-b plane and $\xi_{c}$ is parallel to the c-axis. We obtain $\xi_{a b}=21.1 \AA$ and $\xi_{c}=6.3 \AA$ at zero temperature.

Figure 2 shows $T_{C 2}$ as a function of $\theta$ in an applied field of $5 \mathrm{~T}$. We consider the anisotropic GL theory (2) to fit the data. In this theory the angular dependence of $\mathrm{H}_{\mathrm{C} 2}$ is given by

$$
\begin{gathered}
\mathrm{H}_{\mathrm{c} 2}(\theta)=\mathrm{H}_{\mathrm{c} 2, \| \mathrm{c}}(0)(\cos (\theta) \\
\left.+\mathrm{m}_{\mathrm{ab}} / \mathrm{m}_{\mathrm{c}} \sin ^{2}(\theta)\right)^{-1 / 2},
\end{gathered}
$$

where $\mathrm{H}_{\mathrm{C} 2}, \| \mathrm{C}(0)$ is the upper critical field along the c direction $(\theta=0)$. The anisotropy in the mass is related to the anisotropy in the critical field by $\mathrm{m}_{\mathrm{ab}} / \mathrm{m}_{\mathrm{c}}=\left(\mathrm{H}_{\mathrm{C} 2}, / 1 \mathrm{c} / \mathrm{H}_{\mathrm{C} 2}, \mathrm{~L}^{2}\right)^{2}$. Within GI theory $\mathrm{H}_{\mathrm{C} 2}$ is a linear function of $T$. This is indeed observed in both the parallel and perpendicular critical fields. So the angular dependence of $\mathrm{H}_{\mathrm{C2}}(\theta)$ can be converted to that of $\mathrm{T}_{\mathrm{C2}}(\theta)$ by

$$
\begin{array}{r}
\mathrm{T}_{\mathrm{c} 2}(\theta)=\mathrm{T}_{\mathrm{co}}+\mathrm{H}_{\mathrm{O}} /\left(\alpha \mathrm{H}_{\mathrm{c} 2, / / \mathrm{c}} / \alpha \mathrm{T}\right) \\
\cdot\left[\cos ^{2}(\theta)+\mathrm{m}_{\mathrm{ab}} / \mathrm{m}_{\mathrm{c}} \sin ^{2}(\theta)\right] 1 / 2,
\end{array}
$$

where $\mathrm{T}_{\text {co }}$ is the zero field transition temperature as determined from an extrapolated linear part of $\mathrm{H}_{\mathrm{C} 2} \cdot \mathrm{H}_{\mathrm{O}}=5 \mathrm{~T}$ is the applied field. The solid line labeled by 3D is a fit to Eq.(2) with $\mathrm{m}_{\mathrm{c}} / \mathrm{m}_{\mathrm{ab}}=13.1$.

The angular dependence of upper critical field for $2 \mathrm{D}(\mathrm{d}<\xi)$ superconducting film (3) is given implicitly by the equation

$$
\mid \begin{aligned}
& \mathrm{H}_{\mathrm{C} 2} \cos (\theta) / \mathrm{H}_{\mathrm{C} 2, \frac{1}{\mathrm{C}}} \mid \\
& \quad\left[\mathrm{H}_{\mathrm{C} 2} \sin (\theta) / \mathrm{H}_{\mathrm{C} 2, \| \mathrm{C}}\right]^{2}=1
\end{aligned}
$$

In order to get to the angular dependence of $T_{C 2}$, we use the relations

$$
\begin{aligned}
& \mathrm{H}_{\mathrm{C} 2, \perp \mathrm{C}}=\sqrt{3} \phi_{\mathrm{O}} / \pi \mathrm{d} \xi_{\mathrm{ab}}, \mathrm{H}_{\mathrm{C} 2, \| \mathrm{C}}=\phi_{\mathrm{O}} / 2 \pi \xi_{\mathrm{ab}}^{2}, \\
& \text { and } \xi_{\mathrm{ab}}=\xi_{\mathrm{O}}\left(1-\mathrm{T} / \mathrm{T}_{\mathrm{CO}}\right)^{-1 / 2},
\end{aligned}
$$

where $\phi_{0}$ is the flux quantum. The results of the calculation are shown in Figure 2 labeled by $2 \mathrm{D}$. The $2 \mathrm{D}$ thin film theory predicts a cusp in the angular dependence of $\mathrm{T}_{\mathrm{C} 2}$ at $\theta=90^{\circ}$. However, the cusp behavior is not followed by the data. Therefore the $2 \mathrm{D}$ thin film expression does not describe the data well at $\theta=90^{\circ}$.

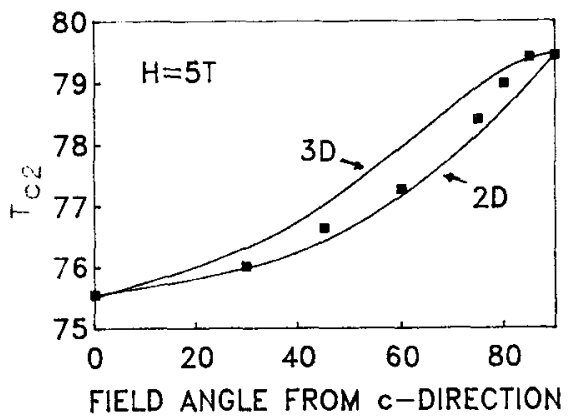

\section{FIGURE 2}

Transition temperature as a function of field angle from c-direction in a field of $5 \mathrm{~T}$.

Now we want to address the dimensional behavior for the layered compound with coupling between the layers. A transition from $3 \mathrm{D}$ to $2 \mathrm{D}$ is expected as one reduces the coupling between the cu-o planes. Based on single crystal data, a 3D-behavior in the layers has been observed for the $90 \mathrm{~K}$ superconductors $(4,5)$ while the oxygen deficient $60 \mathrm{~K}$ superconductor shows a $2 \mathrm{D}$ behavior (4). Our present data tend to indicate that the coupling of the $\mathrm{Cu}-\mathrm{O}$ planes is weaker than that of $90 \mathrm{~K}$ but stronger than that of $60 \mathrm{~K}$ superconductor, so the dimensional behavior of the Cu-O planes lies between 3D and 2D for this sample which shows $T_{C}(50 \%)=81 \mathrm{~K}$ and zero resistance at $78 \mathrm{~K}$.

In conclusion we have performed an anisotropy study for the $c$ axis oriented 1-2-3 film. The results suggest that this coupling is depressed for the films ( $\mathrm{T}_{\mathrm{c}}$ zero $=78 \mathrm{~K}$ ) compared with that of $90 \mathrm{~K}$ superconductor, resulting in a behavior lies between $3 \mathrm{D}$ and $2 \mathrm{D}$ in the coupling of the $\mathrm{Cu}-\mathrm{O}$ planes.

\section{REFERENCES}

(1). See, for example, Iye et al., in Superconducting Materials, edited by S. Nakajima and H. Fukuyama, JJAP Series 1, P46(1988).

(2) .W.E. Lawrence and S. Doniach, in proceedings of the Twelfth International Conference on Low Temperature Physics, Kyoto, 1970, edited by E. Kanda(Keigaku, Tokyo, 1971), p. 361. ;R.A.Klemm and J.R. Clem, Phys. Rev. 21, 1868 (1980).

(3).M. Tinkham, Phys. Rev. 172, 441 (1968).

(4).W. Bauhofer et al., Phys. Rev. Lett. 63,2520 (1989).

(5).U. Welp et al., Phys. Rev. B, $40,5263(1989)$. 